\title{
Significance of downregulation of renal organic cation transporter (SLC47AI) in cisplatin-induced proximal tubular injury
}

\author{
Tomohiro Mizuno ${ }^{1-3}$ \\ Waichi Sato ${ }^{2,3}$ \\ Kazuhiro Ishikawa ${ }^{4}$ \\ Yuki Terao' \\ Kazuo Takahashi \\ Yukihiro Noda ${ }^{5}$ \\ Yukio Yuzawa ${ }^{2}$ \\ Tadashi Nagamatsu' \\ 'Department of Analytical \\ Pharmacology, Meijo University \\ Faculty of Pharmacy, Nagoya, \\ ${ }^{2}$ Department of Nephrology, School \\ of Medicine, Fujita Health University, \\ Toyoake, ${ }^{3}$ Department of Nephrology, \\ Nagoya University School of \\ Medicine, Nagoya, ${ }^{4}$ Department of \\ Neuropsychopharmacology and \\ Hospital Pharmacy, Nagoya University \\ Graduate School of Medicine, Nagoya, \\ ${ }^{5}$ Division of Clinical Sciences and \\ Neuropsychopharmacology, Meijo \\ University Faculty of Pharmacy, \\ Nagoya, Japan
}

This article was published in the following Dove Press journal:

OncoTargets and Therapy

10 July 2015

Number of times this article has been viewed

\begin{abstract}
Background/aim: To elucidate the mechanism responsible for developing acute kidney injury in patients with diabetes mellitus, we also evaluated the issue of whether advanced glycation endproducts (AGEs) influence the expressions of multi antimicrobial extrusion protein (MATE1/ SLC47A1) in tubular cells.

Materials and methods: To detect changing expression of MATE1/SLC47A1 in dose- and time-dependent manners, human proximal tubular epithelial cells were incubated with AGEaggregated-human serum albumin. As a function assay for MATE1/SLC47A1, human proximal tubular epithelial cells were incubated with cisplatin or carboplatin.

Results: On incubation with AGEs, the expressions of MATE1/SLC47A1 were decreased in tubular cells. In addition, the toxicities of cisplatin were increased in tubular cells that had been pretreated with AGEs. However, the toxicities of carboplatin were smaller than that of cisplatin in proximal tubular epithelial cells.
\end{abstract}

Conclusion: The expression of the MATE1/SLC47A1 is decreased by AGEs, which increases the risk for proximal tubular injury.

Keywords: advanced glycation endproducts, cisplatin, SLC47A1, diabetes mellitus, acute kidney injury

\section{Introduction}

Platinum agents are commonly used for the treatment of solid tumors. While these drugs play an essential role in cancer chemotherapy, the development of severe nephrotoxicity can lead to a poor prognosis. Renal injury induced by cisplatin primarily occurs in proximal tubules, ${ }^{1}$ where the tubular injury causes a decrease in the glomerular filtration rate. ${ }^{2}$ Because of this decrease in the glomerular filtration rate, the elimination of cisplatin is delayed in patients with cancer, and, as a result, tubular and glomerular injuries subsequently develop. Organic cation transporter in proximal tubular epithelial cells play an important role in the elimination of cisplatin. ${ }^{3}$ The multi antimicrobial extrusion protein (MATE1/SLC47A1) is expressed at the brush-border membrane in proximal tubular epithelial cells and aids in the excretion of cationic compounds from epithelial cells to the urine. Therefore, MATE1/SLC47A1 plays an essential role in the elimination of cisplatin. ${ }^{4}$

To predict and/or prevent acute kidney injury (AKI) induced by cisplatin, we explored some of the risk factors for AKI. Our findings indicated that diabetes mellitus (DM) was a risk factor for severe AKI that is induced by cisplatin. ${ }^{5}$ However, the mechanism responsible for developing AKI in patients with DM remains unclear. Advanced glycation endproducts (AGEs) interact with the cell-surface receptor

Correspondence: Tomohiro Mizuno Department of Analytical Pharmacology, Meijo University Faculty of Pharmacy, I50 Yagotoyama, Tempaku, Nagoya 468-8503, Japan Email mizunot@meijo-u.ac.jp 
for AGE, which then induces cellular oxidant stress, thus activating the transcription factor nuclear factor- $\kappa \mathrm{B} \cdot{ }^{6,7} \mathrm{An}$ activation of nuclear factor- $\kappa \mathrm{B}$ accelerates the production of inflammatory cytokines ${ }^{8-11}$ and extracellular matrix synthesis; ${ }^{12-15}$ thus, tissue inflammation and cell apoptosis are induced. AGEs are filtered in the glomerulus, and the filtrate moves through the proximal tubules. Although proximal tubular epithelial cells are exposed to AGEs, the effect on the expression of renal transporters is unclear. To elucidate the mechanism responsible for developing AKI in patients with DM, we investigated the issue of whether AGEs influence the expression of MATE1/SLC47A1 in tubular cells.

\section{Materials and methods Agents and antibodies}

Human serum albumin (HSA) was purchased from Bio Verde (Kyoto, Japan). L-Lysine was purchased from Merck (Darmstadt, Germany). D-Glucose was purchased from Wako (Osaka, Japan). QuantiTect Primer Assay (SLC47A1 and GAPDH) was purchased from Qiagen (Venlo, the Netherlands). Power SYBR Green Cell to Cell kit ${ }^{\mathrm{TM}}$ was purchased from Life Technologies (Carlsbad, CA, USA). Rabbit antihuman MATE/SLC47A1 polyclonal antibody was purchased from LifeSpan BioSciences (Seattle, WA, USA). Rabbit IgG as an isotype control and Alexa Flour 647тм goat antirabbit $\mathrm{IgG}$ polyclonal antibody were purchased from Invitrogen (Carlsbad, CA, USA). Human renal proximal tubule epithelial cells were purchased from Takara Bio (Otsu, Japan). Renal epithelial cell growth kit and medium were also purchased from Takara Bio. Fetal bovine serum was purchased from Invitrogen. Six- or 96-well plates were purchased from Becton Dickinson (San Jose, CA, USA). Dimethyl sulfoxide was purchased from Sigma (Tokyo, Japan). Cisplatin and carboplatin were purchased from Wako. XTT-kit was purchased from Roche Applied Science (Penzberg, Germany).

\section{Preparation of AGE-aggregated-HSA (AGE-a-HSA)}

Aggregated-HSA (a-HSA) was prepared as reported previously. ${ }^{16}$ AGE-a-HSA was prepared according to a previous report. ${ }^{17}$ Briefly, a solution of $10 \mathrm{mg} / \mathrm{mL}$ a-HSA, $400 \mathrm{mg} / \mathrm{dL}$ D-glucose, and 0.1 M L-lysine in $0.2 \mathrm{M}$ phosphatebuffered saline was incubated at $50^{\circ} \mathrm{C}$ for 24 hours. The final products were identified by measuring the emission at $430 \mathrm{~nm}$ upon excitation at $360 \mathrm{~nm}$ using a spectrofluorometer (Jasco FP-777; Jasco, Tokyo, Japan). Each solution was sterilized using a filter unit prior to incubation.

\section{Cell cultures}

Human proximal tubular epithelial cells were incubated in renal epithelial cell growth medium with $10 \%$ fetal bovine serum in 6- or 96 -well plate and cultured at $37^{\circ} \mathrm{C}$ for 4 days. All experiments were performed during the third to fifth passage.

\section{Real-time RT-PCR and expression of MATEI/ SLC47AI on proximal tubular epithelial cells under AGE-a-HSA}

To detect changing expression of MATE1/SLC47A1 in dose- and time-dependent manners, human proximal tubular epithelial cells were incubated with a-HSA or AGE-a-HSA. The dose dependency of the effects after a-HSA or AGE-a-HSA treatment was investigated according to previous report; ${ }^{13}$ the cells were incubated with a-HSA or AGE-a-HSA $(0,1.25,2.5$, and $3.75 \mathrm{mg} / \mathrm{mL})$ for 24 hours ( $n=6$, at each groups). A serum-free proximal tubular epithelial cell growth medium was used as a control medium. In addition, to investigate the time dependence of effects after a-HSA or AGE-a-HSA treatment, the cells were incubated with AGE-a-HSA $(2.5 \mathrm{mg} / \mathrm{mL})$ for $0,6,12$, and 24 hours ( $n=6$, at each time point). RNA extraction, reversetranscription to generate cDNA, and quantitative RT-PCR were performed using a Power SYBR green Cells-to-CT kit ${ }^{\mathrm{TM}}$, according to the manufacturer's instructions. Realtime PCR was performed with the 7500 Real-Time PCR System (Applied Biosciences) using SYBR Green primer sets (QuantiTect Primer Assay, SLC47A1, and GAPDH). All data are expressed as relative differences after normalization against GAPDH mRNA.

\section{Flow cytometry analysis and the expression of MATEI/SLC47AI on proximal tubular epithelial cells incubated with AGE-a-HSA}

To investigate the change in expression of MATE1/ SLC47A1, human proximal tubular epithelial cells were incubated for 24 hours in serum-free renal epithelial cell growth medium (control), cell growth medium with a-HSA (2.5 mg/mL), or AGE-a-HSA (2.5 mg/mL). The cells were fixed by treatment with $90 \%$ methanol for 5 minutes at $4{ }^{\circ} \mathrm{C}$ and then incubated with rabbit antihuman MATE1/SLC47A1 polyclonal antibody, or rabbit IgG as an isotype control for 30 minutes at room temperature, following incubation with Alexa Fluor 647 TM gout antirabbit IgG polyclonal antibody for 30 minutes at room temperature in the dark. To detect expression changes on cell surfaces, the geometric mean titers of MATE1/SLC47A1 were evaluated by a BD FACSCanto 
flow cytometer II (Becton Dickinson) using 10,000 events.

The experiments were repeated six times.

\section{Human proximal tubular epithelial cells viability incubated with cisplatin or carboplatin}

To investigate the effects of AGE-a-HSA for the function of MATE1/SLC47A1, human proximal tubular epithelial cells were incubated with cisplatin. The cells were preincubated with a-HSA or AGE-a-HSA ( $2.5 \mathrm{mg} / \mathrm{mL}$ ) for 24 hours ( $\mathrm{n}=6$, at each groups). Proximal tubular epithelial cell growth medium containing sterilized dimethyl sulfoxide $(0.07 \%)$ was used as a vehicle medium. The cells were then washed with phosphate-buffered saline and incubated with cisplatin $(500 \mu \mathrm{M})^{18}$ or carboplatin $(500 \mu \mathrm{M})$ for 24 hours. Cell viability was determined by the XTT assay. XTT assay was conducted according to a previous report. ${ }^{19}$ In brief, a freshly prepared XTT-phenazine methosulfate labeling mixture $(50 \mu \mathrm{L})$ was added to the cell culture medium. The absorbance was measured at $450 \mathrm{~nm}$ after 8 hours of incubation. The cell viability was measured from absorbance, and the viability rates of control (with vehicle) were calculated as $100 \%$.

\section{Statistical analysis}

Continuous data are presented as the mean \pm standard error, and nominal data are presented as numbers (percentages). Statistical differences among multiple groups were analyzed with Kruskal-Wallis tests, followed by the Scheffe test for multiple group comparisons. In these tests, a two-sided value of $P<0.05$ was considered significant. SPSS v22.0 software (SPSS, Chicago, IL, USA) was used for statistical analysis.

\section{Results \\ Expression of MATEI/SLC47AI under the conditions of AGE-a-HSA}

The expressions of MATE1/SLC47A1 mRNA in human proximal tubular epithelial cells under a-HSA or AGE-a-HSA are shown in Figure 1. The expressions of MATE1/ SLC47A1 were decreased in a dose-dependent manner (Figure 1A and B). From these results, the concentrations of a-HSA and AGE-a-HSA were determined to be $2.5 \mathrm{mg} / \mathrm{mL}$. At this concentration, the exposure of a-HSA did not affect the expressions of MATE1/SLC47A1, whereas AGE-a-HSA decreased them in a time-dependent manner.

We next examined the change in the protein levels of MATE1/SLC47A1 using flow cytometry analysis. The expressions of the MATE1/SLC47A1 protein were significantly decreased on incubation with AGE-a-HSA but not with a-HSA alone (Figure 2A and B).

\section{Effect of cisplatin or carboplatin on cell viability by pretreatment with AGE-a-HSA} To evaluate the function of MATE1/SLC47A1 after treatment with AGE-a-HSA, we measured cell viability. In cisplatin incubation, cell viability in the case of AGE-a-HSA incubation was significantly lower than that in control and a-HSA incubation, and no significant differences between vehicle and a-HSA incubation were found (Figure 3). In carboplatin incubation, there were no significant differences among control, a-HSA, and AGE-a-HSA groups (Figure 3). No significant differences were found between vehicle and carboplatin groups (Figure 3).
A

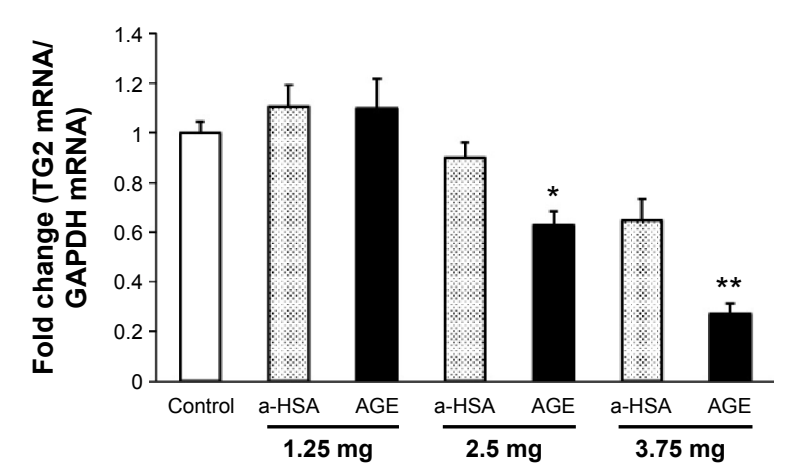

B

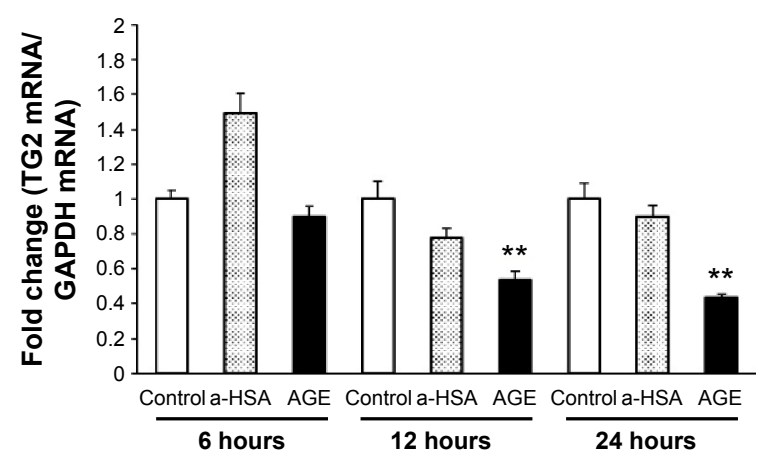

Figure I Effects of AGE-a-HSA on the gene expression of MATEI/SLC47AI.

Notes: (A) Exposure of AGE-a-HSA decreased gene expression of MATEI/SLC47AI in a dose-dependent manner. a-HSA and AGE-a-HSA were incubated with various concentrations for 24 hours. (B) Exposure of AGE-a-HSA decreased gene expression of MATEI/SLC47AI in a time-dependent manner. The concentrations of incubated a-HSA and AGE-a-HSA were $2.5 \mathrm{mg} / \mathrm{mL}$. The amount of MATEI/SLC47AI mRNA was normalized to that of GAPDH and was expressed as a ratio against the control. Bars represent the mean \pm standard error (SE). $* P<0.05$ and $* * P<0.01$ vs control (Scheffe test).

Abbreviations: AGE-a-HSA, advanced glycation endproduct aggregated human serum albumin; MATE, multi antimicrobial extrusion protein; TG2, transglutaminase 2. 

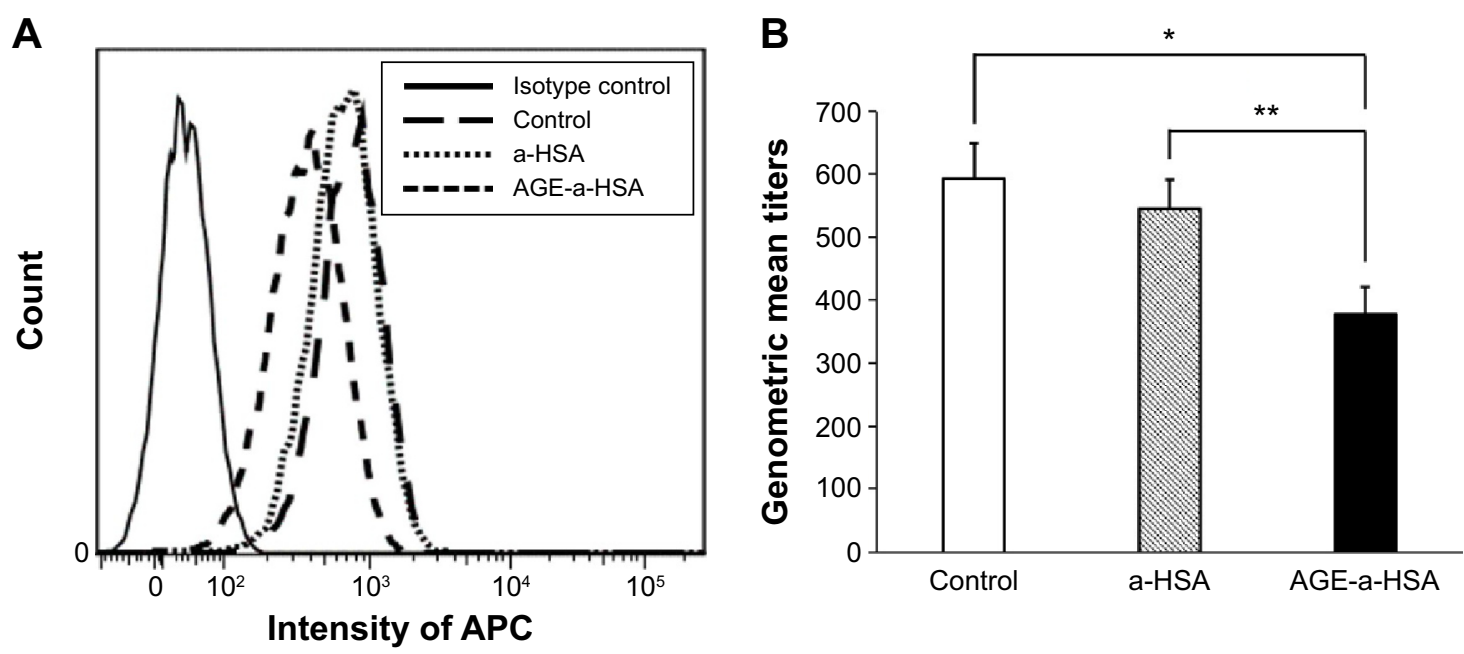

Figure 2 Effects of AGE-a-HSA on the expression of the MATEI/SLC47AI protein.

Notes: (A) Exposure of AGE-a-HSA decreased expressions of MATEI/SLC47AI protein. The concentrations of incubated AGE-a-HSA were 2.5 mg/mL. (B) Geometric mean titers of expressions of MATEI/SLC47AI protein were decreased by exposure to AGE-a-HSA. The geometric mean titers of MATEI/SLC47AI were evaluated by FACS analysis using 10,000 events. Bars represent the mean \pm standard error (SE). $* P<0.05$ vs control and $* * P<0.05$ vs a-HSA (Scheffe test).

Abbreviations: APC, allophycocyanin; AGE-a-HSA, advanced glycation endproduct aggregated human serum albumin; MATE, multi antimicrobial extrusion protein.

\section{Discussion}

In a previous study, we showed that DM was the high-risk factor for cisplatin-induced AKI. ${ }^{5}$ However, no attempt was made to identify the mechanism for the development of AKI in patients with DM. MATE1/SLC47A1, an organic cation transporter in proximal tubular epithelial cells, mediates the tubular secretion of cationic drugs or platinum agents from the blood to the urine. Therefore, some previous reports have suggested that MATE1/SLC47A1 was involved in the nephrotoxicity caused by cisplatin. ${ }^{3,18,20}$ These previous reports also

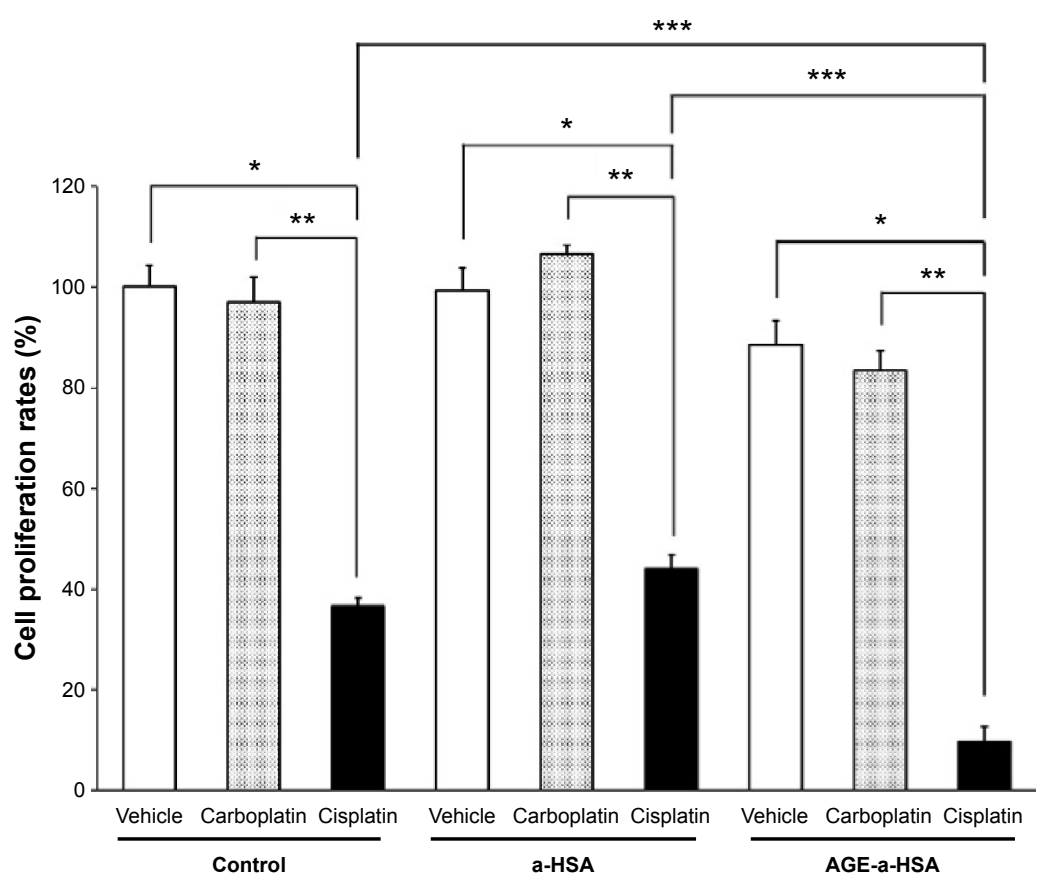

Figure 3 Cell proliferation after 24-hour incubation with cisplatin or carboplatin.

Notes: Human renal tubular cells were pretreated with a-HSA or AGE-a-HSA for 24 hours and incubated in vehicle or a cisplatin containing medium for 24 hours. The cell viability was measured from absorbance, and the viability rates of control (with vehicle) were calculated as $100 \%$. There were no significant differences between vehicle and carboplatin groups. Bars represent the mean \pm standard error $(\mathrm{SE})$. $* P<0.0 \mathrm{I}$ vs vehicle, $* * P<0.0 \mathrm{I}$ vs carboplatin, and $* * * P<0.0 \mathrm{I}$ vs cisplatin with pretreatment of $\mathrm{AGE}$-a-HSA (Scheffe test).

Abbreviation: AGE-a-HSA, advanced glycation endproduct aggregated human serum albumin. 
elucidated the association between the clearance of cationic drugs and the toxicity of cisplatin; however, the function of MATE1/SLC47A1 was unclear in patients with DM.

AGEs promote endothelial permeability and the migration of blood monocytes..$^{21,22}$ Under normal physiological conditions, AGEs are cleared from the body via the kidney, following their degradation by reductase enzymes within cells such as macrophages or mesangial cells. In metabolic conditions, however, there is a marked increase in a number of factors that promote the formation and accumulation of AGEs. ${ }^{23} \mathrm{As}$ a result of the accumulation of AGEs, a marked increase in oxidative stress occurs. ${ }^{24,25}$ Thus, circulating AGEs contribute to the promotion of end-stage renal disease through their accumulation in tissues. ${ }^{26-28}$

AGEs are removed by filtration in the glomeruli, and proximal tubular epithelial cells are consistently exposed to AGEs, although the effects of AGEs on the function of renal transporters remain unclear. In the present study, we used an AGE model protein (AGE-a-HSA), which was produced using a-HSA, and investigated the issue of whether AGEs have the regulation of MATE1/SLC47A1 expression. After incubation in the presence of the AGE-a-HSA preparation, the expression of MATE1/SLC47A1 decreased in higher dose- and time-dependent manners. Interestingly, the toxicity of cisplatin was increased in proximal tubular epithelial cells that had been preincubated with AGEs. However, the toxicity of carboplatin was smaller than that of cisplatin in proximal tubular epithelial cells that had been preincubated with AGEs.

Yokoo et al reported that carboplatin is not transported by organic cation transporter and MATE $1 / \mathrm{SLC} 47 \mathrm{~A} 1 ;{ }^{29}$ thus, the toxicity of carboplatin was not affected by decreasing the expression of MATE1/SLC47A1.

These data indicate that the expression and function of MATE1/SLC47A1 were decreased as the result of AGE incubation, whereas a-HSA incubation did not affect those. In previous studies, AKI models and chronic renal failure models showed a decrease in the level of MATE1 in the kidney. ${ }^{30-33}$ There were no reports showing that AGEs cause a decrease in the expression of the cation transporter in renal tubular cells, thus making this the first report of this phenomenon.

\section{Conclusion}

In conclusion, the expression of MATE1/SLC47A1 is decreased by AGEs, which increases the risk for proximal tubular injury. Based on these results, a new proposed mechanism for cisplatin-induced proximal tubular injury can be made.

\section{Acknowledgment}

This work was supported in part by a 2014 research grant from the Aichi Kidney Foundation.

\section{Disclosure}

KT and WS received research funding from Kyowa Hakko Kirin Co., Ltd., Otsuka Pharmaceutical Co., Ltd., Baxter Limited, Chugai Pharmaceutical Co., Ltd., and Mitsubishi Tanabe Pharma Corporation. The other authors report no conflicts of interest in this work.

\section{References}

1. Dobyan DC, Levi J, Jacobs C, Kosek J, Weiner MW. Mechanism of cis-platinum nephrotoxicity: II. Morphologic observations. J Pharmacol Exp Ther. 1980;213:551-556.

2. Thadhani R, Pascual M, Bonventre JV. Acute renal failure. $N$ Engl J Med. 1996;334:1448-1460.

3. Yonezawa A, Inui K. Importance of the multidrug and toxin extrusion MATE/SLC47A family to pharmacokinetics, pharmacodynamics/ toxicodynamics and pharmacogenomics. Br J Pharmacol. 2011;164: 1817-1825.

4. Yonezawa A, Inui K. Organic cation transporter OCT/SLC22A and $\mathrm{H}(+)$ /organic cation antiporter MATE/SLC47A are key molecules for nephrotoxicity of platinum agents. Biocheml Pharmacol. 2011;81: 563-568.

5. Mizuno T, Ishikawa K, Sato W, et al. The risk factors of severe acute kidney injury induced by cisplatin. Oncology. 2013;85:364-369.

6. Yan SD, Schmidt AM, Anderson GM, et al. Enhanced cellular oxidant stress by the interaction of advanced glycation end products with their receptors/binding proteins. J Biol Chem. 1994;269:9889-9897.

7. Lander HM, Tauras JM, Ogiste JS, Hori O, Moss RA, Schmidt AM. Activation of the receptor for advanced glycation end products triggers a p21(ras)-dependent mitogen-activated protein kinase pathway regulated by oxidant stress. J Biol Chem. 1997;272:17810-17814.

8. Lu C, He JC, Cai W, Liu H, Zhu L, Vlassara H. Advanced glycation endproduct (AGE) receptor 1 is a negative regulator of the inflammatory response to AGE in mesangial cells. Proc Natl Acad Sci US A. 2004;101: 11767-11772.

9. Alves M, Calegari VC, Cunha DA, Saad MJ, Velloso LA, Rocha EM. Increased expression of advanced glycation end-products and their receptor, and activation of nuclear factor kappa-B in lacrimal glands of diabetic rats. Diabetologia. 2005;48:2675-2681.

10. Ide Y, Matsui T, Ishibashi Y, Takeuchi M, Yamagishi S. Pigment epithelium-derived factor inhibits advanced glycation end productelicited mesangial cell damage by blocking NF-kappaB activation. Microvasc Res. 2010;80:227-232.

11. Liang YJ, Jian JH, Liu YC, et al. Advanced glycation end productsinduced apoptosis attenuated by PPARdelta activation and epigallocatechin gallate through NF-kappaB pathway in human embryonic kidney cells and human mesangial cells. Diabetes Metab Res Rev. 2010; 26:406-416.

12. Mizutani K, Ikeda K, Yamori Y. Resveratrol inhibits AGEs-induced proliferation and collagen synthesis activity in vascular smooth muscle cells from stroke-prone spontaneously hypertensive rats. Biochem Biophys Res Commun. 2000;274:61-67.

13. Sasai Y, Iwakawa K, Yanagida K, et al. Advanced glycation endproducts stimulate renal epithelial cells to release chemokines that recruit macrophages, leading to renal fibrosis. Biosci Biotechnol Biochem. 2012; 76:1741-1745.

14. Pugliese G, Pricci F, Romeo G, et al. Upregulation of mesangial growth factor and extracellular matrix synthesis by advanced glycation end products via a receptor-mediated mechanism. Diabetes. 1997; 46:1881-1887. 
15. Hirasawa Y, Sakai T, Ito M, Yoshimura H, Feng Y, Nagamatsu T. Advanced-glycation-end-product-cholesterol-aggregated-protein accelerates the proliferation of mesangial cells mediated by transforminggrowth-factor-beta 1 receptors and the ERK-MAPK pathway. Eur J Pharmacol. 2011;672:159-168.

16. Hirasawa Y, Muramatsu A, Suzuki Y, Nagamatsu T. Insufficient expression of cyclooxygenase-2 protein is associated with retarded degradation of aggregated protein in diabetic glomeruli. J Pharmacol Sci. 2006;102:173-181.

17. Bhatwadekar AD, Ghole VS. Rapid method for the preparation of an AGE-BSA standard calibrator using thermal glycation. J Clin Lab Anal. 2005;19:11-15.

18. Nakamura T, Yonezawa A, Hashimoto S, Katsura T, Inui K. Disruption of multidrug and toxin extrusion MATE1 potentiates cisplatin-induced nephrotoxicity. Biochem Pharmacol. 2010;80:1762-1767.

19. Huang M, Tang SN, Upadhyay G, et al. Embelin suppresses growth of human pancreatic cancer xenografts, and pancreatic cancer cells isolated from KrasG12D mice by inhibiting Akt and Sonic hedgehog pathways. PLoS One. 2014;9:e92161.

20. Yonezawa A, Masuda S, Yokoo S, Katsura T, Inui K. Cisplatin and oxaliplatin, but not carboplatin and nedaplatin, are substrates for human organic cation transporters (SLC22A1-3 and multidrug and toxin extrusion family). J Pharmacol Exp Ther. 2006;319:879-886.

21. Esposito C, Gerlach H, Brett J, Stern D, Vlassara H. Endothelial receptor-mediated binding of glucose-modified albumin is associated with increased monolayer permeability and modulation of cell surface coagulant properties. J Exp Med. 1989;170:1387-1407.

22. Kirstein M, Brett J, Radoff S, Ogawa S, Stern D, Vlassara H. Advanced protein glycosylation induces transendothelial human monocyte chemotaxis and secretion of platelet-derived growth factor: role in vascular disease of diabetes and aging. Proc Natl Acad Sci US A. 1990;87: 9010-9014.

23. Sourris KC, Forbes JM. Interactions between advanced glycation endproducts (AGE) and their receptors in the development and progression of diabetic nephropathy - are these receptors valid therapeutic targets. Curr Drug Targets. 2009;10:42-50.
24. Miyata T, Hori O, Zhang J, et al. The receptor for advanced glycation end products (RAGE) is a central mediator of the interaction of AGE-beta2microglobulin with human mononuclear phagocytes via an oxidant-sensitive pathway. Implications for the pathogenesis of dialysis-related amyloidosis. J Clin Invest. 1996;98:1088-1094.

25. Miyata T, Ishikawa N, van Ypersele de Strihou C. Carbonyl stress and diabetic complications. Clin Chem Lab Med. 2003;41:1150-1158.

26. Makita Z, Radoff S, Rayfield EJ, et al. Advanced glycosylation end products in patients with diabetic nephropathy. $N$ Engl J Med. 1991; 325:836-842.

27. Makita Z, Bucala R, Rayfield EJ, et al. Reactive glycosylation endproducts in diabetic uraemia and treatment of renal failure. Lancet. 1994; 343:1519-1522.

28. Bucala R, Makita Z, Vega G, et al. Modification of low density lipoprotein by advanced glycation end products contributes to the dyslipidemia of diabetes and renal insufficiency. Proc Natl Acad Sci US A. 1994;91: 9441-9445.

29. Yokoo S, Yonezawa A, Masuda S, Fukatsu A, Katsura T, Inui K. Differential contribution of organic cation transporters, OCT2 and MATE1, in platinum agent-induced nephrotoxicity. Biochem Pharmacol. 2007; $74: 477-487$

30. Nishihara K, Masuda S, Ji L, Katsura T, Inui K. Pharmacokinetic significance of luminal multidrug and toxin extrusion 1 in chronic renal failure rats. Biochem Pharmacol. 2007;73:1482-1490.

31. Matsuzaki T, Morisaki T, Sugimoto W, et al. Altered pharmacokinetics of cationic drugs caused by down-regulation of renal rat organic cation transporter $2(\mathrm{~S} 1 \mathrm{c} 22 \mathrm{a} 2)$ and rat multidrug and toxin extrusion 1 (Slc47a1) in ischemia/reperfusion-induced acute kidney injury. Drug Metab Dispos. 2008;36:649-654.

32. Morisaki T, Matsuzaki T, Yokoo K, et al. Regulation of renal organic ion transporters in cisplatin-induced acute kidney injury and uremia in rats. Pharm Res. 2008;25:2526-2533.

33. Nakagawa S, Masuda S, Nishihara K, Inui K. mTOR inhibitor everolimus ameliorates progressive tubular dysfunction in chronic renal failure rats. Biochem Pharmacol. 2010;79:67-76.
OncoTargets and Therapy

\section{Publish your work in this journal}

OncoTargets and Therapy is an international, peer-reviewed, open access journal focusing on the pathological basis of all cancers, potential targets for therapy and treatment protocols employed to improve the management of cancer patients. The journal also focuses on the impact of management programs and new therapeutic agents and protocols on

\section{Dovepress}

patient perspectives such as quality of life, adherence and satisfaction The manuscript management system is completely online and includes a very quick and fair peer-review system, which is all easy to use. Visit http://www.dovepress.com/testimonials.php to read real quotes from published authors. 